\title{
Epistemic Criteria for Designing Limit Tasks on a Real Variable Function
}

\section{Criterios Epistémicos para el Diseño de Tareas sobre Límite de una función en una variable Real}

\author{
Daniela Araya Bastias* \\ ORCID iD 0000-0002-3395-3348 \\ Luis R. Pino-Fan ** \\ ORCID iD 0000-0003-4060-7408 \\ Iván G. Medrano*** \\ ORCID iD 0000-0003-4910-1235 \\ Walter F. Castro ${ }^{* * * *}$ \\ ORCID iD 0000-0002-7890-681X
}

\begin{abstract}
This article aims at presenting the results of a historical-epistemological study conducted to identify criteria for designing tasks that promote the understanding of the limit notion on a real variable function. As a theoretical framework, we used the Onto-Semiotic Approach (OSA) to mathematical knowledge and instruction, to identify the regulatory elements of mathematical practices developed throughout history, and that gave way to the emergence, evolution, and formalization of limit. As a result, we present a proposal of criteria that summarizes fundamental epistemic aspects, which could be considered when designing tasks that allow the promotion of each of the six meanings identified for the limit notion. The criteria presented allow us to highlight not only the mathematical complexity underlying the study of limit on a real variable function but also the richness of meanings that could be developed to help understand this notion.
\end{abstract}

Keywords: Limit. Task design. Onto-Semiotic Approach.

\section{Resumen}

El objetivo de este artículo es presentar los resultados de un estudio de tipo histórico-epistemológico, que se llevó a cabo para identificar criterios a considerar en el diseño de tareas para promover la comprensión de la noción de

\footnotetext{
* Magíster en Matemática por la Universidad de Santiago de Chile (USACH). Estudiante del Doctorado en Educación Matemática de la Universidad de Los Lagos (ULAGOS), Osorno, Chile. E-mail: danielaandrea.araya2@alumnos.ulagos.cl.

** Doctor en Didáctica de la Matemática por la Universidad de Granada (UGR). Académico del Departamento de Ciencias Exactas, Universidad de Los Lagos (ULAGOS), Osorno, Chile. E-mail: luis.pino@ulagos.cl.

**** Magíster en Matemática por la Universidad de Santiago de Chile (USACH). Estudiante del Doctorado en Educación Matemática de la Universidad de Los Lagos (ULAGOS), Osorno, Chile. E-mail: imedrano83@gmail.com.

***** Doctor en Didáctica de la Matemática por la Universidad de Granada (UGR). Académico de la Universidad de Antioquia (UdeA), Medellín, Colombia. E-mail: walter.castro@udea.edu.co.
} 
límite de una función en una variable real. Como marco teórico utilizamos el Enfoque Onto-Semiótico (EOS) del conocimiento y la instrucción matemáticos, para identificar los elementos regulativos de las prácticas matemáticas que se desarrollaron a lo largo de la historia y que dieron paso al surgimiento, evolución y formalización de la noción límite. Como resultado, se presenta una propuesta de criterios, que resumen aspectos epistémicos fundamentales, que se podrían considerar para el diseño de tareas que permiten promover cada uno de los seis significados identificados para la noción de limite. Los criterios presentados permiten resaltar no sólo la complejidad matemática subyacente al estudio del límite de una función en una variable real, sino la riqueza de significados que podrían desarrollarse para ayudar a la comprensión de esta noción.

Palabras clave: Límite. Diseño de Tareas. Enfoque Ontosemiótico.

\section{Introduction}

The notion of limit is the basis of infinitesimal calculus, as it is a fundamental concept for the comprehension and development of other concepts, such as continuity, derivative, integration, and series (ELIA et al., 2009; PARAMESWARAN, 2007). In the last few years, multiple studies have examined the complexity of teaching and learning limits on a real variable function. These papers inform difficulties classified in three categories: a) epistemological obstacles (CORNU, 1991; ARTIGUE, 1995; SIERPINSKA， 1985; TALL; SCHWARZENBERGER, 1978); b) cognitive difficulties regarding the concept of infinity and the complexity of the formal concept $\varepsilon, \delta$ (BARAHMAND, 2017; MAMONA-DOWNS, 2001; BLÁSQUEZ et al., 2006); and c) didactic challenges concerning limits teaching (CAGLAYAN, 2015; MONAGHAN,1991; FUENTE; ARMENTEROS; FONT, 2012).

Research has also evidenced difficulties regarding the tasks that teachers use to promote the learning of limits, such as the lack of meaningful activities and the emphasis on algebraic techniques and procedures (HEINE, 1988; ARTIGUE, 1995; KOIRALA, 1997) that negatively affect the development of students' deep notion comprehension. In this regard, Koirala (1997) emphasizes that teachers teach rules, and students apply them not understanding what they are doing.

In response to this trend, several investigations propose tasks to promote a meaningful learning of this notion. For example, Keene, Hall, and Duca (2014) designed tasks to help students learn the "formal" meaning of limit through activities that promote the dynamic and intuitive notion of the concept. These tasks are based on the theory of 'Realistic Mathematics Education'. Irazoqui and Medina (2013) design tasks called Didactic Activities for Learning, to teach limits using Winplot software. Similarly, Soler de Dios (2014) designed tasks using fractals to foster intuitive limits learning through their geometric representation.

Other studies concerning task design are focused on implementation and how their application affects students' learning. For instance, Fuente, Armenteros, and Font (2012) 
studied tasks concerning limits and concluded that its triple representation -graphical, numerical, symbolic- is paramount for learning this notion and that tasks that only promote the intuitive study of limit cause difficulties with the notion of actual infinity.

Two main aspect are notable: 1) There is a significant number of studies (ELIA et al., 2009; PARAMESWARAN, 2007; JONES, 2014; FERNÁNDEZ-PLAZA; RUIZ-HIDALGO; RICO, 2015) that use task design to enhance the learning of limits or to examine students' ideas on limits; however, there are no studies that propose criteria to design tasks that consider the rich and complex nature of limits on a real variable function. 2) Some methodologies provide guidelines to design tasks, but they fall short in including criteria for both the complexity and diversity of meanings. In this regard, we take on to study the meanings of limits as they appear in the history of mathematics and to identify criteria that could be used to design meaningful tasks to improve the learning and teaching of limits on a real variable function.

\section{Theoretical Framework: The Onto-Semiotic Approach to Mathematical Knowledge and Instruction}

In order to study the meanings associated to limits on a real variable function concept along with history, we used some theoretical-methodological tools from the Onto-Semiotic Approach (OSA) of mathematical cognition and instruction (GODINO; BATANERO, 1994; GODINO; BATANERO; FONT, 2007; FONT; GODINO; GALLARDO, 2013). This approach is used to articulate primary mathematical objects- Linguistic elements, situations/problems, concepts/definitions, propositions/ properties, procedures, and arguments- that are organized in what is called: configurations. The notion of configuration "responds to the need of identifying the types of objects and processes that intervene and emerge in the mathematical practices used to solve the situations-problems" (GODINO; BATANERO; FONT, 2019, p. 39). The configurations emerge in the system of practices that refers to "any action or manifestation (linguistic or otherwise) carried out by someone to solve mathematical problems, to communicate the solution to other people, to validate and generalize that solution to other contexts and problems" (GODINO; BATANERO, 1994, p. 334). The mathematical practices can be personal or shared by a group within an institution (institutional practices). Godino and Batanero (1994, p. 337) define the institutional practices as "The institutional system of practices, associated to a field of problems, is constituted by the practices considered as significative to solve a field of problems C and shared in the heart of an institution I".

The notion of practices plays an essential role in the epistemological and didactic 
perspective, because when someone inquiries about the meaning of limit, it is found that it refers to the system of practices that a person carries out (personal meaning), or that is shared within an institution (institutional meaning) to solve situation-problems. In mathematical practices, ostensive objects (symbols, graphs) and non-ostensive objects (concepts, propositions) that we evoke when doing mathematics and that are textually, orally, graphically, or even gesturally represented, intervene.

New objects emerge from the system of operative and discursive mathematical practices, and these show their organization and structure. When an agent performs and evaluates a mathematical practice, it activates a conglomerate of basic entities or primary mathematical objects made of problems, linguistic elements, concepts, propositions, procedures, and arguments. Problems are the core of the activity; language can represent the remaining entities and serves as an instrument for action; arguments justify the procedures and propositions that connect concepts. These primary mathematical objects connect to form configurations of objects. These configurations can be socio-epistemic (networks of institutional objects) or cognitive (networks of personal objects) depending on whether the primary mathematical objects are put into play in institutional or personal practices, respectively.

The presence of the primary mathematical objects previously mentioned is linked, respectively, with processes of problem-posing, communication, definition, algorithmization, enunciation, and argumentation. The systemic analysis of the primary mathematical objects and the underpinning processes are named as onto-semiotic configuration (PINO-FAN; GODINO; FONT, 2015), and can be epistemic or cognitive. Specifically, the notion of epistemic configuration allowed the reconstruction of the holistic meaning or holo-meaning (WILHEMI; GODINO; LACASTA, 2007; PINO-FAN; GODINO; FONT, 2011), through the identification of the partial meanings of the notion of limit, from the research and historical documents of infinitesimal calculus. Furthermore, the epistemic onto-semiotic configuration helps to determine criteria for task design that promotes the study of the meanings of limit on a real variable function.

\section{Methodology}

To establish valid criteria for task design that enhance the partial meanings of limits on a real variable function, it is necessary to identify epistemic configurations associated with each one of the six identified partial meanings of limits. The methodology proposed to revisit 
primary, secondary, and tertiary bibliographic sources to identify meanings associated with limits throughout history. An epistemic configuration refers to a set of meanings, objects, and mathematical practices that give rise to a mathematics concept. A mathematical object exists in terms of its meanings, relationships among them, and problems that are solved.

Primary sources (CAUCHY, 1833; D’ALEMBERT, 1766; EUCLIDES, 2007; NEWTON, 1736; NEWTON, 2011; DEDEKIND, 2014) provided information related to the notion of limit in the real context in which it was originated, and how it evolved through time. Secondary sources (BRUNSCHVICG, 1945; BOYER, 2016; COLLETTE, 1985; ZELLINI 2004) and tertiary (CANTORAL; FARFÁN, 2004; MEDRANO; PINO-FAN, 2016), enable comparison among interpretations made with the results from recent investigations.

The strategy to select the information is through the analysis of the materials written, considered as quasi-observable instruments, which in a way replace the observer and the interviewer in inaccessible situations (WOODS, 1987).

\section{Epistemic Configurations Meanings for Limits on a real variable function}

To establish criteria for task design that enhance the partial meanings of limits on a real variable function, it is necessary to identify epistemic configurations associated with each one of the limits six partial meanings identified. In what follows, the epistemic configurations are presented.

\subsection{Epistemic Configuration 1 (EC1): The notion of approximation according to Eudoxus and Archimedes}

This configuration is associated with the measurement of immeasurable magnitudes as well as volume and area computing. Eudoxus, Archimedes well as Euclid's recompilation is the historical base to investigate epistemic configurations. Primary mathematical objects that emerge in this configuration will be presented.

\section{Linguistic elements}

The representations used are verbal, graphic, and symbolic. The verbal representations refer to terms as a magnitude measurement, geometric ratio, geometrical continuum, and potential infinity. The graphic refers to geometric shapes and representations of approximation procedures. The symbolic is characterized by the use of letters of the Greek alphabet to label geometrical shapes (rectangle, parallelograms, etc.) 


\section{Concepts/Definitions}

Two notions are essential in this configuration; the first refers to magnitudes and proportions, and the second to infinity. Pythagoras established a correspondence between geometric elements and numbers, regarding "magnitude". This correspondence gives rise to "proportion" between geometric magnitudes and whole numbers (BRUNSCHVICG, 1945). The Pythagorean notions of "magnitude" and "proportion" could not be applied to immeasurable magnitudes, according to the Greek conception of numbers. The solution to this problem was proposed by Eudoxus, who established the concept of "proportion", which was subsequently described and elaborated in the book V of Euclid's Elements:

Magnitudes are said to be in the same ratio, first to second and third to fourth, whenever equal-times multiples of the first and third either together exceed than or together are equal to or together are less than equal-times multiples of the second and fourth, respectively, taken in a corresponding order (EUCLIDES, 2007, p. 184-185).

Eudoxus' main contribution to this configuration refers to the applicability of proportion to commensurable and incommensurable magnitudes that generalizes Pythagoras' proportion ideas. Furthermore, the proportion applies to the comparison of geometrical shapes, as was commented by Collette (1985, p. 97):

This definition has the advantage of applying not only to numbers but also to geometric elements since the ratio between spheres can be equal to the ratio between cubes.

The second contribution refers to infinity proposed by Aristotle as "a set of objects is unlimited if when trying to identify each of its elements it is not possible to form a whole unit with them since there will always be a non-considered element (potential infinity)" (ZELLINI, 2004, p. 12). Infinity had to be considered as potential, as Aristotle was not familiar with the concept of actual infinity. The idea of potential infinity prevailed over centuries until Cantor questioned it in the XIX century.

\section{Situations/Problems}

Some geometry problems could be solved by establishing proportions between incommensurable and commensurable magnitudes that gave rise to two configurations: (a) Geometrical relations between incommensurable magnitudes and geometric magnitudes in general. (b) Numerical relations between geometric magnitudes, including incommensurable magnitudes.

\section{Properties/Propositions}

The method of exhaustion is the basis of this configuration, whose basis is in the Archimedean principle, interpreted by Euclides (2007, p. 88) in the following terms:

Given two unequal magnitudes, if from the greater be subtracted greater than the half, 
and so on continually, there will be left some magnitude which will be less than the lesser given magnitude

\section{Procedures}

The method of exhaustion, an algorithm of finite iteration, is the preferred procedure to deal with approximation problems. Eudoxus used proportions that involve infinite cardinality numerical sets. A procedure used to work with numerical sets is the 'double reduction to absurd' that, through the denial of the proposition to be proved, avoids working with infinite sets, which leads to operating with a finite number of elements.

\section{Arguments}

The propositional results that emerge rely on axiomatic-deductive reasoning that considers primitive objects that give rise to new objects are defined, and properties and relations are established. The axiomatic deductive method based on valid data and deduction rules, presented in the Euclid' Elements, became the preferred argumentation model. The principles used to justify are the method of double reduction to the absurd, which is based on the logical principle of the excluded third party; and the trichotomy law (for each given pair of ratios of positive integers it is needed to $\frac{m}{n}<\frac{r}{s}$ ó $\frac{m}{n}=\frac{r}{s}$ ó $\frac{m}{n}>\frac{r}{s}$ ).

\subsection{Epistemic Configuration 2 (EC2): Limits based on indivisibles}

In the XVI and XVII centuries, research and development of mathematics were strongly influenced by other disciplines' requirements, as well as by the need of solving concrete problems. The need for using mathematical knowledge also involves the search for more effective methods than those available in the Elements, due to the logical complexity of the exhaustion method. The infinitesimal methods are reconsidered and modified, which leads to infinitesimal calculus. The primary mathematics objects present in this configuration are:

\section{Linguistic elements}

The linguistic elements are expressed in a descriptive language based on an intuitive geometric foundation. Magnitudes or geometric objects are expressed as infinitely small and infinity of infinitely small elements. Regarding the linguistic, graphic element, the geometric shapes of Euclidean geometry are used to represent specific movements (Kepler's problems), representations of physical problems in geometric shapes (Stevin and Oresme's problems), and representations of geometric procedures for the calculation of area and volumes (Cavalieri's problems). Concerning the symbolic aspect, the lack of adequate symbology complicates the exposition of the theory, as well as the comprehension of it. 


\section{Concepts/Definitions}

In this configuration, the indivisible concept is essential, which is considered as an essential part of "infinitely small" geometric objects (CAVALIERI, 1635, cited in BRUNSCHVICG, 1945). Geometric magnitudes (longitude, surface, and volumes) generated by magnitudes of inferior order that are added in unlimited form, are conceived.

\section{Situations/Problems}

The problems studied are mostly the same that Greek geometers addressed: a) quadrature problems; b) cubature problems. Additionally, situations originated from the application of mathematics to other disciplines, and daily life. Kepler studied astronomic problems; one of them refers to the radius of the vector joining the planet to the Sun sweeps out equal areas in equal times (BOYER, 2016).

\section{Propositions/Properties}

It is considered that every geometric magnitude is generated by an infinity of elements that correspond to a magnitude that is of an inferior order, which is added in an unlimited way to reproduce the given magnitude. A line is generated by infinite points, a surface by the addition of an unlimited number of parallel lines to the base of the plane shape, a volume by the addition of an unlimited number of parallel planes to the bases of the volume. These procedures originate a great proposition known as the Cavalieri's Theorem:

If two plane figures have equal altitudes and if sections made by lines parallel to the bases and at equal distances from them are always in the same ratio, then the volumes of the two plane figures are also in this ratio (BOYER, 2016, p. 417).

\section{Procedures}

The indivisibles procedure considers that every geometric magnitude is formed by an undetermined number of elements (indivisibles) corresponding to a strictly inferior geometric magnitude. However, these elements are limited by the magnitude of a superior order. Thus, the relations that are known or that can be established between magnitudes of a superior order enable them to operate indirectly with the indivisible set contained in them, not considering the quantity of these indivisibles. For example, the procedures that Cavalieri used established a univocal correspondence between the indivisibles of two geometric objects, which were compared to verify if they had the same area or volume, as appropriate (BOYER, 2016).

\section{Arguments}

The arguments postulate that surfaces and solids are composed by generative elements obtained by the cut of surfaces (or solids), by lines (or planes) parallel to the bases, which enables to determine the relationship between unknown magnitudes comparing them with the 
known ones. For example, the procedures that Cavalieri used.

\subsection{Epistemic Configuration 3 (EC3): The intuitive notion of limits in Newton infinitesimal calculus.}

The emergence of the analytic geometry contributes to Newton's proposal in solving physics problems, denying the concept of indivisibles, and proposing a new meaning for the limits' dynamic character. Newton uses finite limits to represents dynamic particle character. Newton's proposal is referring to a new epistemic configuration because of the physical features, which brings into play the following elements.

\section{Linguistic elements}

The linguistic elements of a verbal nature are characterized by introducing a vocabulary of a technical nature to describe the fundamental theoretical elements, whose definitions are given based on relationships with other mathematical elements and concepts. This is how the terms are introduced: fluent quantities, fluxions, moments of fluent quantities, evanescent quantities, nascent quantities, last sums and reasons of evanescent quantities, sum and prime reasons of nascent amounts.

The physics vocabulary refers to velocity, flow, the velocity of flow, magnitude of moment. Concerning linguistic elements of graphic nature, it is observed that geometric shapes represent procedures based on analytic geometry tools. The symbolic linguistic elements are expressed in algebraic language; the first letters of the alphabet: $a, b$, $c$, etc., are used to designate constant quantities; the last letters of the alphabet: $v, x, y, z$ are used for flowing quantities (variable quantities). Furthermore, a special notation is introduced to designate fluxions of a flowing quantity: $\dot{v}, \dot{x}, \dot{y}, \dot{z}$. Additionally, any flowing quantity moments are represented by $x, y, z \ldots$; and the increments or decreases of flowing quantities as: $\dot{x}=x_{0}, \dot{y}=$ $y o, \dot{z}=z o$; where $o$ represents an infinitely small increment or decrease (PINO-FAN, 2014). Mathematical procedures are expressed in algebraic language that acquires a high level of abstraction.

\section{Concepts/Definitions}

Based on the conception of indefinitely small quantities, Newton introduces two essential concepts: fluents and fluxions, which he defines as "[...] those quantities which I consider as gradually and indefinitely increasing, I shall hereafter call fluents or flowing quantities [...]" (NEWTON, 1736, p. 20). In the same fashion, he defines fluxion as "[...] the velocities by which every fluent is increased by its generating motion, (which I may call 
Fluxions, or simply Velocities or Celerities) [...]" (NEWTON, 1736, p. 20). Another essential concept in the development of the method is the moment of fluents:

The moments of flowing quantities (that is, their indefinitely small parts, by the accession of which, in indefinitely small portions of time, they are continually increased,) are as their velocities of flowing or increasing (NEWTON, 1736, p. 24).

Due to criticism that the fluxions method received from mathematicians at that time, Newton proposed the so-called first and ultimate ratios of nascent and evanescent quantities.

[...] for by the ultimate velocity is meant that with which the body is moved, neither before it arrives at its place and the motion ceases, nor after; but at the very instant it arrives, that is, that velocity with which the body arrives at its last place, and with which the motion ceases. And in like manner, by the ultimate ratio of evanescent quantitates is to be understood the ratio of the quantities, not before they vanish, nor afterwards, but with which they vanish. In like manner, the first ratio of nascent quantities is that with which they begin... There is a limit which the velocity at the end of the motion may attain, but not exceed; and there is the ultimate velocity. And there is the like limit in all quantities and proportions that begin and cease to be [...] (NEWTON, 2011, p. 170).

It is important to mention that these definitions are descriptive and were established based on an analogy with the physical concept of velocity. Newton was aware of the controversy that his definitions could cause, he expressed:

It may be also argued, that if the ultimate ratios of evanescent quantities are given, their ultimate magnitudes will be also given; and so, all quantities will consist of indivisibles... But this objection is founded on a false supposition, for those ultimate ratios with which quantities vanish are not truly the ratios of ultimate quantities, but the limits to which the ratios of quantities, decreasing without end, always converge; and to which they may approach nearer than by any difference, but can never go beyond, nor attain to, unless the quantities are diminished indefinitely (NEWTON, 2011, p. 169-171)

\section{Situations/Problems}

Newton intended to solve two problematic situations of an entirely physic nature, which are detailed hereafter:

i) The length of the space described being continually (that is, always) given; to find the velocity of the motion at any time proposed. ii) The velocity of the motion being continually given; to find the length of the space described at any time proposed (NEWTON, 1736, p. 19).

In order to solve the first situation, the concepts of fluents and fluxions are introduced at first instance with which the modern interpretation of the first problem is: given by one equation that expresses the relation between fluent quantities, determine the equation that expresses the relation between its fluxions. The second problem can be interpreted as the inverse problem of the former: acknowledged an equation that expresses the relation between fluxions of fluent quantities determines the equation that expresses the relation of the fluent quantities.

\section{Procedures}

Procedures were geometric-analytic, based on Cartesian geometry. However, in the 
work Philosophiae Naturalis Principia Mathematica he moves away from the theory proposed by Descartes and works with algebraic procedures using equations and variables. A modern interpretation (COLLETTE, 1985) is:

Given the equation of the curve $x^{3}-a x^{2}+a x y-y^{3}=0$, calculate fluxions. Newton proposed replacing the variables $x$ e $y$ by $x+\dot{x} o$ o e $y+\dot{y} o$ respectively, obtaining

$$
\begin{aligned}
& \left(x^{3}+3 \dot{x} o x^{2}+3 \dot{x}^{2} o^{2} x+\dot{x}^{3} o^{3}\right)-\left(a x^{2}+2 a \dot{x} o x+a \dot{x}^{2} o^{2}\right) \\
& +\left(a x y+a \dot{x} o y+a \dot{y} o x+a \dot{x} \dot{y} o^{2}\right)-\left(y^{3}+3 \dot{y} o y^{2}+3 \dot{y}^{2} o^{2} y+\dot{y}^{3} o^{3}\right)=0
\end{aligned}
$$

Then, he eliminated the equation $x^{3}-a x^{2}+a x y-y^{3}$, since it is equal to zero. Subsequently, he divides the resulting equation by $o$ and, in the obtained equation, eliminates all the expressions in which any factor of $o$ appears. Thus, finally, the expression $3 \dot{x} x^{2}-$ $2 a \dot{x} x+a \dot{x} y+a \dot{y} x-3 \dot{y} y^{2}=0$ is obtained.

\section{Propositions/Properties}

Changing operative principles, the method of fluxions is based in (for the use of indefinitely small quantities and the moments of flowing quantities), for evanescent quantities, first quantities, and increasing or decreasing increments of these quantities, two propositions to substantiate this new theory are introduced:

Lemma 1. Quantities, and ratios of quantities, which in any finite time constantly tend to equality, and which before the end of that time approach so close to one another that their difference is less than any given quantity, become ultimately equal (NEWTON, 2011, p. 157).

The latter propositions introduced intuitive ideas on the constant tendency of two variable quantities that tend to equality in a finite period. The uninterrupted decrease characterizes the tendency to zero by the difference of these variable quantities. Another instance refers to an equivalent proposition, but in a geometric context (Figure 1):

Lemma 2. If in any figure AacE, comprehended by the straight lines Aa and AE and the curve acE, any number of parallelograms $\mathrm{Ab}, \mathrm{Bc}, \mathrm{Cd}$, etc., are inscribed upon equal bases $\mathrm{AB}, \mathrm{BC}, \mathrm{CD}$, etc., and sides, $\mathrm{Bb}, \mathrm{Cc}, \mathrm{Dd}$, parallel to the side $\mathrm{Aa}$ of the figure; and if the parallelograms aKbl, bLcm, cMdn, etc., are completed; if then the width of these parallelograms is diminished and their number increased indefinitely: I say that the ultimate ratios which the inscribed figure $\mathrm{AKbLcMdD}$, the circumscribed figure AalbmendoE, and the curvilinear figure AabcdE, have to one another are ratios of equality (NEWTON, 2011, p. 157). 


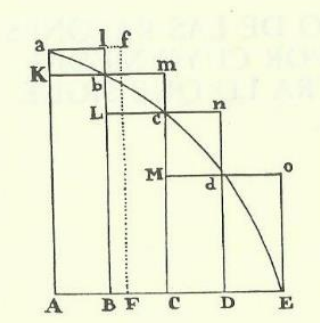

Figure 1 - Geometric Representation Newton's Lemma 2 Source: NEWTON (2011, p. 157)

\title{
Arguments
}

The arguments that justify the replacement of $x$ e $y$ by $x+\dot{x} o$ and $y+\dot{y} o$ respectively, are based on infinitesimals that rely upon algebra and geometry; as Collette (1985, p. 110) states,

\begin{abstract}
Since moments like $\dot{x} o, \dot{y} o$ are annexes or infinitely small expansions of the fluent quantities $x$ e $y$ during the infinitely small-time intervals, it follows that these quantities $x$ e $y$, after an infinitely small-time interval, are converted into $x+\dot{x} o$ e $y+$ $\dot{y} o$... In this way, it is possible to substitute in the same equation instead of $x$ e $y$.
\end{abstract}

\subsection{Epistemic Configuration 4 (EC4): The infinitesimals idea of Leibniz}

The infinitesimal calculus developed by Leibniz is based on philosophic considerations on mathematics, in contrast to the work of Newton, whose focus was put on the creation of effective mathematical tools. The focal point of Leibniz was the foundation of infinitesimal calculus. In the following sections, we analyze the primary mathematical objects that comprise this configuration.

\section{Linguistic elements}

The verbal-linguistic elements identified are expressions, such as infinitesimal or differential of a variable. These expressions are related since the second concept derives from the infinitesimal notion. Regarding linguistic and graphic elements, the use of Euclidean geometry shapes and the use of graphs can be distinguished. Leibniz's particular triangle, formed by an infinitely small part of the tangent to a curve, in one point, and infinitely small portions of parallels can be represented by a Euclidean triangle (Figure 2). Regarding symbols, Leibniz proposed the notation for differentiation-the variables are $x, y$ and their differentials are represented by $d x, d y$. Leibniz proposes the integral symbol $\int y d x$ to indicate the infinite sum of ordinates under a curve $y$. In this sense, several authors (e.g., PINO-FAN, 2014) point out that the symbol used by Leibniz for the differential, and in general, the new language introduced by him, allowed the development of the theorems and applications that support today's 
Infinitesimal Calculus.

\section{Concepts/Definitions}

The concepts that can be recognized are a particular triangle, the differential of a variable, and the continuum. Leibniz considered the composition of the continuum as a central issue in differential and integral calculus. The conception of continuum went through three progressive stages: the first stage conceives continuum as formed by infinite parts, in which such parts would be considered as indivisibles (represented by planes and lines, etc.); the second stage denies the existence of indivisibles and proposes that the continuum is formed by infinitely small parts (infinitesimals); in the last stage Leibniz changes his conception of the division of the continuum and denies the existence of ultimate components of it.

\section{Situations/Problems}

Two main problematic situations can be identified, and the first is supporting and formalizing the continuum concept; the other problematic situation is the use of the differential calculus (PINO-FAN, 2014); the third problem refers to determine the equation of a tangent to a curve, the curvature and cubature problems.

\section{Procedures}

The use of operational activity with infinitesimal quantities and infinite processes can be identified. One such example refers to the sum of a convergent infinite series. The problem of constructing the tangent to a curve at a given point is translated into infinitesimal calculus; calculating differentials of the given variables in the equation that represents the curve and determining the tangent direction through the quotient of these infinitesimal quantities. Cantoral and Farfán (2004, p. 94) present a modern interpretation of using characteristic triangles, which is the one provided by

To determine the longitude of a curve, the characteristic triangle of a curve $y=f(x)$ is used, in which the differential in variable $x$ is considered as $d x$ and the corresponding increment $d y$ is calculated in the variable $y=f(x)$. The triangle, where ds is the infinitesimal increment in the graphic $y=f(x)$, is completed. This can be observed in Figure 2:

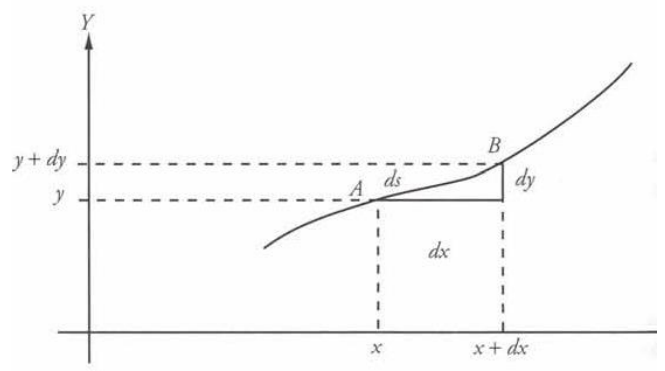

Figure 2 - Leibniz's Characteristic Triangle

Source: Cantoral and Farfán (2004, p. 94) 
Leibniz maintained that the infinitesimal arc $\mathrm{AB}$ is indistinguishable from the chord $\overline{A B}$, and then the curved triangle is identical to the right-angled triangle formed in it. Then, applying the Pythagoras' theorem: $d s^{2}=d x^{2}+d y^{2}$. Thus, $d s=\sqrt{1+\left(\frac{d y}{d x}\right)^{2}} d x$, which represents the longitude of the infinitesimal arc, in terms of differences $d x$ and $d y$. Hence, the longitude of the curve from a $P\left(x_{1}, y_{1}\left(x_{1}\right)\right)$ point to a $Q\left(x_{2}, y_{2}\left(x_{2}\right)\right)$ point is the sum of all the infinitesimal arcs, in other words: $L(P, Q)=\int_{x_{1}}^{x_{2}} \sqrt{1+\left(\frac{d y}{d x}\right)^{2}} d x$. Where $L(P, Q)$ represents the longitude of the curve from $P$ to $Q$. Furthermore, an operational activity between conventional numbers and these new mathematical objects, which are not clearly defined, characterized, nor represented, can be distinguished. However, there is an informal extension of the traditional operations (addition, subtraction, multiplication, division) to these new objects.

\section{Propositions/Properties}

The main properties regarding operation and application of infinitesimal calculus in an advantageous way are the introduction of the characteristic triangle that links the operational activity with infinitely small magnitudes, of the indivisibles geometry, with elements of Euclidean geometry; a relationship that allows studying geometric properties of curves in the Cartesian plane; the direction of the curve and the velocity on change of direction. Additionally, a differential algebra is formulated as well.

Another property worth highlighting is the one signaled by Brunhschwicg (1945, p. 236) "[...] Leibniz brings into play infinity in the finite generation. In this sense, the science of the infinite is used to find the finite quantities". In this respect, Leibniz, cited by Brunhschwicg (1945, p. 237), stated that: "[...] equality can be considered as an infinitely small inequality, and inequality can be approximated to equality as required [...]". The modern interpretation of this claim is the following: given $a$ and $b$ real numbers, then $\forall \varepsilon>0$, if $|a-b|<\varepsilon \Leftrightarrow a=$ $b$.

\section{Arguments}

In this configuration, arguments refer to infinite processes (infinitesimal calculus), which are based on actual infinity. Additionally, these infinite processes are characterized by a continuous process, based on the general principle of continuity. Regarding the general principle of continuity, Leibniz states:

\footnotetext{
With this law of continuity that excludes a leap in changing, also agrees on the following: the case of rest can be considered as a special case of motion, indeed, the case of vanishing or minimal motion, and that the case of equality can be considered as a case of vanishing inequality (LEIBNITZ, 1695, cited in BRUNSCHVICG, 1945, p. 238).
} 
For Leibniz, there is a distinction between unfolding processes of things in general and the actual state of them; the unfolding is characterized by not admitting leaps or interruptions. On the other hand, the actual state of mathematical objects and things, in general, is conceived as a result of infinite processes. A finite quantity is generated by an infinite process where infinitely small quantities -infinitesimals- and equality as an infinitely small inequality.

\subsection{Epistemic Configuration 5 (EC5): Pre-formal conceptions of limits}

The epistemic configuration refers to geometry, physics, and commerce applications. The applications compel a reconsideration of the discipline foundations to make it suitable for generalization and application. This configuration is the beginning of the transition from preconceptions of limits to conceptions of limits, as are known today.

\section{Linguistic elements}

The verbal-linguistic elements that can be identified by terms such as magnitude, successive values, indefinitely approximation, or as small as required; these represent the supposition that the set of real numbers does not have leaps and that they are continuous (known today as the density of rational and irrational numbers). The graphic linguistic elements are identified as geometric representations of curves of functions, but they are studied in a dynamic way. The linguistic elements of the symbolic type are $f(x+\alpha)-f(x)$, which represents an infinitely small magnitude, only if $\alpha$ is a small number; $d x$ represents an infinitely small quantity that can be considered equal to zero.

\section{Concepts/Definitions}

The definition of infinitesimal provided by Euler:

[...] an infinitely small quantity is simply an evanescent quantity, and therefore actually equal to zero. For Euler, calculus of the infinitely small consists in the study of the geometric ratio of the infinitely small quantities (COLLETTE, 1985, p. 195).

Euler proposes that small quantities can be considered equal to zero. A modern interpretation of this idea is provided by Collette (1985), who explains that, if $d x$ represents an infinitely small quantity, then $d x=0$, consequently $a \pm d x=a$, where $a$ is any finite quantity, then in general $a \pm n d x=a$, thus $a \pm n d x-a=0$. Then the geometric ratio of the equality is $(a \pm n d x) / a=1$. Collette (1985, p. 195) described the notion proposed by Euler as "the infinitely small quantities tend to zero in comparison to the finite quantities, and, additionally, can be rejected when they are involved in these finite quantities". 
Another notion of limit worth highlighting is the one proposed by D'Alembert (1766,

p. 542),

One calls a magnitude a limit of another magnitude, when the second may approximate to the first closer than by a given magnitude, however small one may suppose it, without however that the approaching magnitude may surpass the magnitude that it approaches, in such a manner that the difference of such a quantity and its limit is unassignable.

D'Alembert describes a notion of limit in which the second and the first magnitude cannot coincide, i.e., both magnitudes are as close as one could wish. While D'Alembert showed a significant advance, it still lacks precision. For example, Medrano and Pino-Fan (2016, p. 309) stated that

[...] regarding the approximation to the first quantity, is it with higher or lower values? How can the difference between the approximation and the limiting magnitude with the 'as little as one could wish' magnitude, be compared? Does this last expression refer only to positive quantities?

It is worth highlighting that D'Alembert points out that his conception of infinitesimal quantities cannot be zero:

a quantity is something or nothing; if it is something, it has not yet vanished; if it is nothing it has vanished. The supposition that there is an intermediate state between these two is a chimera (COLLETTE, 1985, p. 215).

D'Alembert suggests that the notion of limits is the basis of calculus (BOYER, 2016).

On the other hand, in the book "Cours d'Analyse", Cauchy introduces the following definitions:

A variable quantity is a quantity that one considers as being able to receive successively several different values. On the contrary a constant quantity is a quantity that receives one fixed and determined value. When the values successively attributed to the same variable approach a fixed value indefinitely, in such a way as to end up by differing from it as little as one could wish, this last value is called the limit of all the others (CAUCHY, 1833, p. 17).

Cauchy's idea of limits shows that the approximation to a fixed value can have a difference as little as one could wish, which may be a generalization of D'Alembert conception. Furthermore, Cauchy proposes a new definition for infinitesimals:

When the successive numerical values of the same variable decrease indefinitely in such a way as to fall below any given number, this variable becomes what one calls an infinitesimal or an infinitely small quantity. A variable of this kind has zero for its limit (CAUCHY, 1833, p. 17).

It is essential to mention that Cauchy's notion of infinitesimal caused that the concept of differential defined by Leibniz would take a secondary role, as Boyer states (1987, p. 648):

The differential, that had played with Leibniz and his successors the primary role, he relegated to a subsidiary role, although he was aware of its operational facility. If $d x$ is a finite quantity, the differential $d y$ of $y=f(x)$ is defined simply as $f^{\prime}(x) d x$. 
Furthermore, that notion permitted Cauchy to introduce the concept of continuity of a function: "The function $f(x)$ is continuous within given limits of the variable $x$ if between these limits an infinitely small increment $i$ in the variable $x$ always produces an infinitely small increment, $f(x+i)-f(x)$, in the function itself" (BOYER, 1987, p.648). Cauchy's notion of continuity parallels the definition used today in calculus books; moreover, it allowed Weierstrass later to introduce the concepts of lateral limits in a $x_{o}$ number, a fundamental condition for a function limit in a number $x_{o}$ to exist (BOYER, 2016).

\title{
Situations/Problems
}

The problems that compel this configuration can be found in diverse areas, such as geometric, physic, commercial, and economic problems. For example, D'Alembert exposes the specific problem of a circle area:

\begin{abstract}
For example, suppose we have two polygons, one inscribed in a circle and the other circumscribed; it is clear that one may increase the number of sides as much as one wishes, and in that case each polygon will approach ever more closely to the circle circumference; the perimeter of the inscribed polygon will increase and that of the circumscribed polygon will decrease, but the perimeter or edge of the first will never surpass the length of the circumference, and the second will never be smaller than that same circumference; the circle circumference is therefore the limit of the increase of the first polygon and of the decrease of the second. (D'ALEMBERT, 1766, p. 542)
\end{abstract}

In the previous cite, the notion of limit, which is a value that "is never reached", is clearly stated.

\section{Procedures}

It is worth noting Euler's procedure used to determine a differential. Collette (1985) provides a modern interpretation: to determine the difference $y=x^{2}$, it is considered $w$ and the increment of $x$ and $n$ the increment of $y$, then $y+n=(w+x)^{2}$, which implicates $n=w^{2}+$ $2 w x$. Thus, the ratio of the increments, is $w / n=1 /(w+2 x)$, as $w=0$, it can be deduced that $\left(d\left(x^{2}\right)\right) / d x=2 x / 1$. In this procedure, it is possible to observe the assumption that infinitesimals can be zero, just as Euler proposed.

\section{Propositions/Properties}

One of the most transcendental properties identified in this configuration is the use of algebra limits proposed by D'Alembert (1766, p. 542):

(1) If two magnitudes are the limit of the same quantity, the two magnitudes will be equal. (2) Suppose $A \cdot B$ is the product of two magnitudes $A, B$. Let us suppose that $C$ is the limit of the magnitude $A$, and $D$ the limit of the quantity $B$; I say that $C \cdot D$, the product of the limits, will necessarily be the limit of $A \cdot B[\ldots]$.

Furthermore, Euler used infinitesimal properties considering them as "zeros" just as mentioned before, and Cauchy utilized propositions in which the infinitesimal' as little as one 
wishes', was used. On the other hand, Cauchy and Bolzano independently developed the concept of convergence of a sequence; although Bolzano introduced earlier the concept and criteria of convergence, it is Cauchy's work that prevails to this day with the following proposition "a sequence $S_{n}$ converges to a limit if, and only if, the difference between $S_{p}$ and $S_{q}$ for any values of $p$ and $q$ greater than $n$ is less in absolute value than any given value, considering $n$ sufficiently large" (MEDRANO; PINO-FAN, 2016, p. 312). This property helped to formally develop studies of sequence convergence, particularly to develop the completeness of the real numbers.

\section{Arguments}

The arguments are based on the different conceptions of infinitesimals. For Euler, the infinitesimal is an infinitely small magnitude that can be considered as zero. Additionally, Cauchy points out that the infinitesimal is an infinitely small quantity that tends to zero, while D'Alembert rejects the conception of infinitesimal since, for him, infinitesimal calculus must be based on the notion of limits (although, in a sense, in a pre-formal way).

\subsection{Epistemic Configuration 6 (EC6): Weierstrass limits notions}

Euler, D'Alembert, and Cauchy's mathematical advances helped formalize the current limits' concept. However, this was possible because of the formulation of both the function concept and the real numbers' completeness. These new concepts helped the arithmetization of Calculus; the foundations are no longer on geometry nor algebra. According to Valdivé and Garbin (2008, p. 495):

The concept of limit was defined from the arithmetic of real numbers, leaving aside the infinite processes and with them infinitesimals as differences, increments, and decreases. The transition of calculus from algebra to arithmetic, installed a view of infinitely small quantities in terms of limits and excluded the continuous variability, which made calculus move away from infinitesimals.

Due to the arguments based on the complexity of real numbers, the notion of limit of Weierstrass is considered as a partial meaning with the following configuration:

\section{Linguistic Elements}

The verbal-linguistic elements that can be identified by expressions as variable, function, series, and limit of a function, the numerical value of a function, real numbers, convergent sequences, continuity, and absolute value. Additionally, the graphic linguistic elements, such as representations of real numbers as intervals, lines, and the use of graphs of functions in the context of analytic geometry. Regarding the symbolic aspect, notations like $x$ 
(as magnitude or variable), $f(x)$ (as a numerical value of a function or variable dependent of $x$ ), Greek letters $\varepsilon, \eta$ (that represent small positive quantities), $\left|x-x_{0}\right|$ (distance between $x$ and $x_{0}$ numbers), $L$ (value of limit when it is a real number), can be identified.

\section{Concepts/Definitions}

The limits Dedekind' definition is:

We say that a variable magnitude $\mathrm{x}$, which passes through successive definite numerical values, approaches a fixed limiting value $\alpha$ when during the process $\mathrm{x}$ lies finally between any two numbers between which $\alpha$ itself lies, or, what amounts to the same, when the difference $x-\alpha$ taken absolutely becomes finally less than any given value different from zero (DEDEKIND, 2014, p. 101).

Due to the advances and the formalization of real numbers by Cantor, Dedekind, and Weierstrass, the later could define the notion of limits in the following terms:

If, given any $\varepsilon$, there is an $\eta_{0}$ such that for $0<\eta<\eta_{0}$ the difference $f\left(x_{0} \pm \eta\right)-L$ is less in absolute value than $\varepsilon$, then $L$ is the limit of $f(x)$ at $x=x_{0}$ (BOYER, 2016, p. 696).

It should be noted that the notion of infinitesimal is equivalent to the number $\eta$ and the number $\varepsilon$. The frames contain descriptive information, written in the form of text.

Furthermore, the notion of limits provided by Weierstrass contributes to calculus arithmetization, as it deals exclusively with real numbers considering the set of real numbers as a complete ordered field, the field operations, and the operations that derive from them. Currently, the Greek letter $\eta$ is substituted by the Greek letter $\delta$. It is important to mention that that notion introduces the notion of lateral limits implicitly since it studies the limit in $x_{o} \pm \eta$, where $\eta$ is a positive number. Furthermore, the notion of limits has been taken into convergence, with generalizations in metric and topological spaces, the theory of filters and nets.

It is worth noting that the Weierstrass limit' definition eliminates infinitesimals use in mathematics until the introduction of Robinson's Non-Standard Analysis.

\section{Situations/Problems}

There are diverse problems in this period; however, the problems that make the notion of limit emerge are typical of mathematics, in the sense of formalizing the concept of limit and not admitting ambiguity.

\section{Procedures}

They are based on the algebra of the operations with real numbers and the absolute value properties. Furthermore, it uses the functions' representations in graphs in the context of analytic geometry.

\section{Propositions/Properties}

In this regard, it is worth noting the algebraic properties of the arithmetic operations 
defined in the set of real numbers, which implicates that the set of real numbers may be a body. The relation of the order of real numbers that allow defining a metric as the absolute value; and the completeness of real numbers that makes possible using a notion of infinitesimal that is different from the ones previously defined.

\section{Arguments}

Weierstrass considers an infinitesimal as a continuous variable, Collette (1985, p. 355) interprets it as:

a continuous variable is a variable in which $x_{0}$ is any value of the value set attributed to the variable and $\delta$ is any positive number, there are other values of the variable in the interval $\left(x_{0}-\delta, x_{0}+\delta\right)$.

The use of the completeness of real numbers helped Weierstrass to overlook the concept of infinitesimal proposed by Cauchy, D’Alembert, Euler, and Leibniz.

So far, we have presented the historical-epistemological journey for the understanding of the notion of limit of a real variable function, analyzing from the practices that originated it to those that allowed its formalization. The mathematical richness observed in each of these configurations (associated to the different practices) can be used to propose activities that allow the progressive development for understanding this notion, from intuitive stages to its formalization. However, it should be noted that this notion has continued to develop from the point of view of mathematics itself, and has suffered formalizations and generalizations with respect to the elements presented in this article. One of such formalizations and generalizations is that which refers to a topological point of view; for example, in the book Calculus by Apostol (1967, p. 127) it is pointed out that:

Let $f$ be a function defined in some open interval containing a point $p$, although we do not insist that $f$ be defined at the point $p$ itself. Let $A$ be a real number. The equation $\lim _{x \rightarrow p} f(x)=A$ is read: The limit of $f(x)$, as $x$ approaches $p$, is equal to $A$, or $f(x)$ approaches $A$ as $x$ approaches $p$. It is also written without the limit symbol, as follows: $f(x) \rightarrow A$ as $x \rightarrow p$.

However, this article has not developed a type of configuration for the meanings associated to this type of generalizations, since its objective was to study the initial stages of understanding the meanings of the notion of limit that could generate that the student could develop progressive learning from the intuitive, pre-formal, and formal meanings until arriving at this type of more general definitions.

\section{Epistemic Configurations for Limits Designing' Tasks}

Based on both the study of partial meanings of limit on real variable function and 
primary mathematical objects, it was possible to determine fundamental aspects of every partial meaning that are expressed in epistemic configurations (language, concepts, procedures, propositions and arguments), that could be used to design tasks that take epistemic configurations into account. Table 1 summarizes fundamental epistemic aspects of each epistemic configurations, which constitute aspects that highlight the mathematic complexity of each of the six meanings of limit, which can be considered for the design of tasks in the instruction of the notion.

The configurations presented agree with Mallart, Font, and Malaspina's proposal (2016), regarding the aspects of mathematical richness for what they denominate a good problem. For the OSA, the meaning of a mathematical object is in accordance with mathematical practices in which this is included; Table 1 shows diverse configurations of meanings in which the mathematic study of a limit on a real variable function is put into play. This illustrates the vast complexity of the concept of limits, as well as the task design for its instruction.

The didactic suitability (MALLART; FONT; MALASPINA, 2016) and the appropriateness of each epistemic configuration to comprehend the concept of limit on a real variable function, remain to be explored. Epistemic configurations can be used to identify emerging mathematical objects within mathematical practices, as well as to recognize possible conflicts of meaning that may appear during discussions with students (CASTRO; GODINO; RIVAS, 2011). Table 1 not only shows the diverse meanings in each epistemic configuration, but also the verbal, geometric, and symbolic resources used to discuss limits.

The epistemic configurations are linked to descriptors (BREDA; PINO-FAN; FONT, 2017), known as mathematic suitability' criteria, that might be considered not only for tasks' design but also for mathematics teaching, to be known: a) The partial meanings (constituted of definitions, properties, procedures, etc.), are representative samples of the complexity of the mathematical notion chosen to be taught as part of the curriculum; b) The use of different modes of expression (verbal, graphic, symbolic...), treatments and conversations amongst students are part of one or more of the constituents of partial sense; c) Relevant processes in mathematical activity (modeling, argumentation, problem-solving, connections, etc.).

The following is an example of a task taken from the Chilean Mathematics' curriculum (MINISTERIO DE EDUCACIÓN DE CHILE, 1998), chosen to illustrate the epistemic configurations shown in Table 1. The activity concerns the construction of the Sierpinski Triangle to analyze the area and perimeter of triangles (Figure 3). 


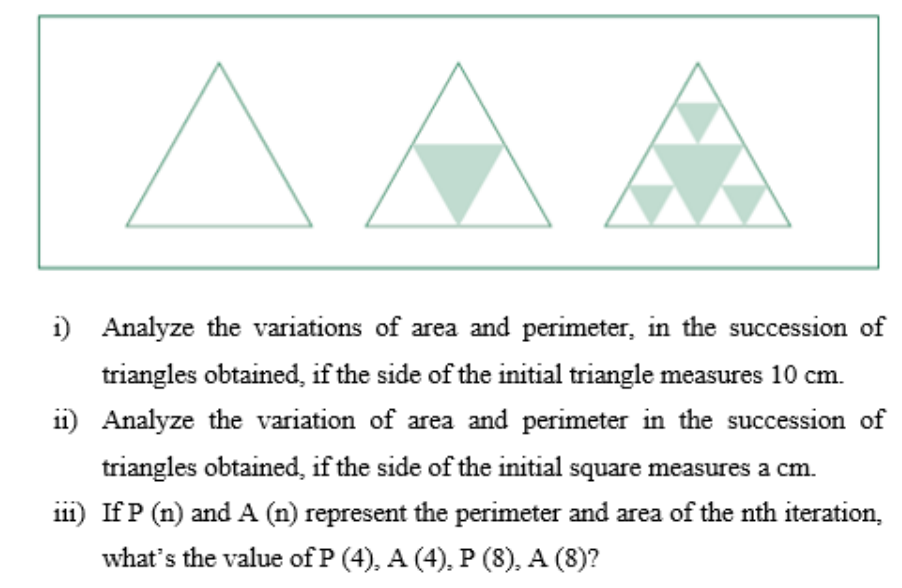

Figure 3 - Sierpinski Triangle Activity

Source: Ministerio de Educación de Chile (1998, p. 15)

The Chilean Ministry of Education proposes that in this activity, students must, intuitively, discover that $\lim _{n \rightarrow \infty} A(n)=0$ and $\lim _{n \rightarrow \infty} P(n)=\infty$. Students on this level do not know Weierstrass' notion of limits (EC6).

The activity analysis distinguishes that the linguistic elements put into play for the solution are verbal or symbolic, and they represent areas and perimeters of triangles. Furthermore, the geometric figures used are equilateral triangles. It is observed that the succession and the number of triangles are related to the concept of potential infinity, and that magnitudes are used to express the area and perimeter of the triangles that underlies the correspondence between geometric elements and numbers.

Regarding situations/problems, the problem refers to identifying relations among the perimeters and areas of triangles. The procedure refers to the use of the exhaustion method because an infinite iteration of triangles is made. Furthermore, the properties/propositions that the exhaustion method uses is based on the Archimedean axiom. It is possible that students' answers would not explicitly include this proposition, but they would use it in an intuitive way: 'the more iterations performed, the smaller the area of the triangles obtained becomes'. Finally, the solution could be based both on the iterations and calculation performed on the area and perimeter of the triangles in a finite quantity of iterations. Based on the latter, the arguments will be deductive.

Thus, based on the analysis performed on primary mathematical objects involved in the activity, it can be said that task development is consistent within the Epistemic Configuration of 'Limits as an approximation in Greek Mathematics' (EC1). 
Table 1 - Primary objects of each Epistemic Configuration for the notion of limit

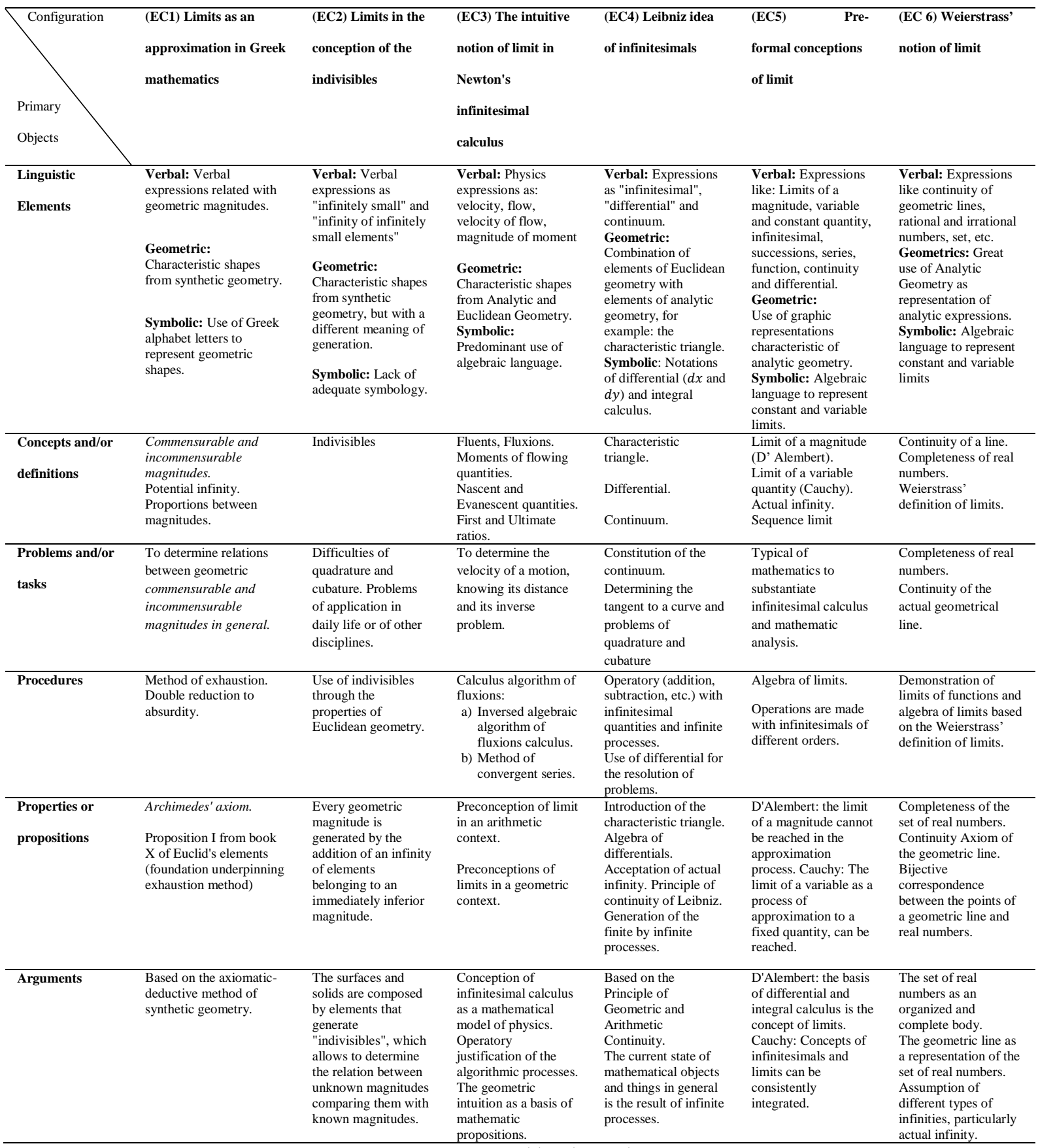

Source: Prepared by the authors

\section{Conclusions}

The historic-epistemological research conducted on limits on a real variable function, helped identifying its genesis and development through time; it is worth highlighting that it had various facets during its institutionalization process, which evolved along with emerging problems in different periods. Many of these problems are characteristic of mathematics and are related to infinity, real numbers as an ordered and complete field, and function. The concept 
of limits did not have a continuous and progressive path, but it had moments of rupture with previous knowledge and retrogression, grounded in the problems and obstacles in different epochs.

Considering that history offers evidence about the formulation and the development of limits, it seems appropriate to consider these relevant aspects to design tasks that consider the epistemic configurations. These epistemic considerations provide information to design mathematical tasks, as well as, to identify representational resources and meaning conflicts that emerge during mathematical practices.

The complexity of Figure 1 evidences that the study of limits on a real variable function requires a profound knowledge of the historical notion development; this document intends to be used during task design by offering diverse configurations as necessary representational elements for the instruction of limit on a real variable function. It is also helpful to approach the study of limits in a systematic way and accept that the comprehension of the concept is developed through time. Table 1 could be used in discussing even simple looking limit tasks (e.g., $\lim _{x \rightarrow \infty} x$ or the example in Figure 3), because the primary mathematical objects can be identified in one of the epistemic configurations summarized in this paper, this could be led to consider meanings and representations that could be ignored by tasks designers and that play an essential role in teaching and learning limits.

Task design research highlights that design and implementation depend on the theoretical framework that supports them. Theoretical tools help guide task design, and they can be applied in the classroom. One challenge is designing the task using the criteria identified in this article, based on the theoretical-methodological tools provided by the OSA, to link tasks items to every meaning in order to promote a comprehensive understanding.

\section{Acknowledgments}

This article has been developed within the research project Fondecyt 1200005 framework, funded by Agencia Nacional de Investigación y Desarrollo (ANID) of Chile.

\section{References}

ARTIGUE, M. La enseñanza de los principios del cálculo: problemas epistemológicos, cognitivos y didácticos. In: GÓMEZ, P. (ed.). Ingeniería didáctica en educación matemática. México: Grupo Editorial Iberoamérica, 1995. p. 97-140.

APOSTOL, T. Calculus: One-Variable Calculus, with an Introduction to Linear Algebra. New 
York: John Wiley \& Sons, 1967.

BARAHMAND, A. The Boundary Between Finite and Infinite States Through the Concept of Limits of Sequences. Journal of Science and Mathematics Education, Taiwan, v. 15, n. 3, p. 569-585, nov. 2017.

BLÁZQUEZ, S.; ORTEGA, T.; GATICA, S.; BENEGAS, J. Una conceptualización de límite para el aprendizaje inicial de análisis matemático en la universidad. Revista Latinoamericana de Investigación en Matemática Educativa, Ciudad de México, v. 9, n. 2, p. 189-209, jul. 2006.

BREDA, A.; PINO-FAN, L. R.; FONT, V. Meta Didactic-Mathematical Knowledge of Teachers: Criteria for The Reflection and Assessment on Teaching Practice. EURASIA Journal of Mathematics, Science and Technology Education, Turkey, v.13, n. 6, p.1893-1918, jun. 2017.

BRUNSCHVICG, L. Las Etapas de la Filosofía Matemática. Buenos Aires: Lautaro, 1945.

BOYER, C. Historia de la matemática. Madrid: Alianza Editorial, 1987.

BOYER, C. Historia de la matemática. Madrid: Alianza Editorial, 2016.

CANTORAL, R.; FARFAN, R. Desarrollo Conceptual del Cálculo. Ciudad de México: Thomson Editores, 2004.

CAGLAYAN, G. Math majors' visual proofs in a Dynamic environment: the case of limit of a function and the $\varepsilon-\delta$ approach. International Journal of Mathematical Education in Science and Technology, London, v. 46, n 6, p. 797-823, mar. 2015.

CASTRO. W. F.; GODINO, J. D.; RIVAS, M. Razonamiento algebraico en educación primaria: Un reto para la formación inicial de profesores. UNIÓN, São Paulo, v. 25, p.73-88, mar. 2011.

CAUCHY, M. A. Résumés Analytiques. Turin: De l'imprimerie royale, 1833.

COLLETTE, J. Historia de las matemáticas I. Madrid: Siglo veintiuno de España editores, 1985.

CORNU, B. Limits. In: TALL, D. (ed.). Advanced Mathematical Thinking. Dordrecht: Kluwer Academic Press, 1991. p. 153-166.

D’ALEMBERT, J. Encyclopédie ou Dictionnaire Raisonné des Sciences des Arts et des Métiers Paris: Boiasson, David, Le Breton, Durand, 1766. v. 9.

DEDEKIND, R. ¿Qué son y para qué sirven los números?: Y otros escritos sobre los fundamentos de la matemática. Madrid: Alianza Editorial, 2014.

ELIA, I.; GAGATSIS, A.; PANAOURA, A.; ZACHARIADES, T.; ZOULINAKI, F. Geometric and Algebraic Approaches in the concept of "limit" and the impact of the "Didactic Contract".

International Journal of Science and Mathematics Education, Taiwan, v. 7, p. 765-790, jan. 2009.

EUCLIDES. Elementos. Madrid: Gredos, 2007.

FERNÁNDEZ-PLAZA, J. A.; RUIZ-HIDALGO, J.; RICO, L. Razonamientos basados en el concepto de límite finito de una función en un punto. Enseñanza de las Ciencias, Barcelona, n. 33, v. 2, p. 211 229 , mar. 2015.

FONT, V.; GODINO, J. D.; GALLARDO, J. The emergence of objects from mathematical practices. Educational Studies in Mathematics, Amsterdam, v. 82, p. 97-124, jan. 2013. 
FUENTE, A.; ARMENTEROS, M.; FONT, V. Análisis de un Proceso de Estudio sobre la Enseñanza del límite de una. Bolema, Rio Claro, v. 26, n. 42B, p. 667-690, abr. 2012.

GODINO, J. D.; BATANERO, C. Significado institucional y personal de los objetos Matemáticos. Recherches en Didactique des Mathématiques, Grenoble, v. 14, n. 3, p. 25-355, sep. 1994.

GODINO, J. D.; BATANERO, C.; FONT, V. The onto-semiotic approach to research in mathematics education. ZDM Mathematics Education, Eggenstein-Leopoldshafen, v. 39, n.1, p. 127-135, jan.2007.

GODINO, J. D.; BATANERO, C.; FONT, V. The onto-semiotic approach: implications for the prescriptive character of didactics. For the Learning of Mathematics, New Westminster, v. 39, n. 1, p. 37-42, apr. 2019.

HEINE, M. K. Resequencing Skilss and Concepts in Applied Calculus using the computer as a tool. Journal for Research in Mathematics Education, Reston, v. 19, n. 1, p. 3-25, jan. 1988.

IRAZOQUI, E.; MEDINA, A. Estudio preliminar de aproximación al concepto de límite de una función. Theoria, Concepción, v. 22, n. 1, p.21-31, jul. 2013.

JONES, S. R. Calculus limits involving infinity: the role of students' informal dynamic reasoning. International Journal of Mathematical Education in Science and Techonology, London, v. 46, n. 1, p. 105-126, jul. 2014.

KEENE, K.; HALL, W; DUCA, A. Sequence limits in calculus: using design research and building on intuition to support instruction. ZDM Mathematics Education, Eggenstein-Leopoldshafen, v. 46, p. 561-574, jun. 2014.

KOIRALA, H. P. Teaching of calculus for student's conceptual understanding. The Mathematics Educator, Georgia, v. 20, p. 52-62, jul. 1997.

MALLART, A.; FONT, V.; MALASPINA, M. Reflexión sobre el significado de qué es un buen problema en la formación inicial de maestros. Perfiles Educativos, Ciudad de México, v. 38, n. 152, p.14-30, jun. 2016.

MAMONA-DOWNS, J. Letting the intuitive bear on the formal: A didactic approach for the understanding of the limits of a sequence. Educational Studies in Mathematics, Amsterdam, v. 48, p. 259-288, nov. 2001.

MEDRANO I.; PINO-FAN L. Estudios de Comprensión de la Noción Matemática de Límite Finito desde el Punto de Vista Histórico. REDIMAT, Barcelona, v. 5, n. 1, p. 287-323, oct. 2016.

MINISTERIO DE EDUCACIÓN DE CHILE. Matemática. Funciones y Procesos Infinitos: Programa de Estudio Cuarto Año Medio Formación Diferenciada Humanístico-Científica. Available in: https://www.curriculumnacional.cl/614/w3-propertyvalue-77612.html. Access in: day month. Year.

MONAGHAN, J. Problems with the language of limits. For the Learning of Mathematics, White Rock, v. 11, n. 3, p. 20-24, nov. 1991.

NEWTON, I. The Method of Fluxions and Infinite. London: Henry Woodfall, 1736.

NEWTON, I. Principios Matemáticos de la Filosofía Natural. Madrid: Alianza Editorial, 2011.

PARAMESWARAN, R. On understanding the notion of limits and infinitesimal quantities, 
International Journal of Science and Mathematics Education, Taiwan, v. 5, p. 193-216, may. 2007.

PINO-FAN, L. Evaluación de la faceta epistémica del conocimiento didáctico-matemático de futuros profesores de bachillerato sobre la derivada. 2014. Thesis (Doctorado en Didáctica de la Matemática) - Departamento de Didáctica de la Matemática, Universidad de Granada, Granada, 2014.

PINO-FAN, L. R.; GODINO, J. D.; FONT MOLL, V. Faceta epistémica del conocimiento didácticomatemático sobre la derivada. Educação Matemática Pesquisa, São Paulo, v. 13, n. 1, p.141-178, abr. 2011.

PINO-FAN, L.; GODINO, J. D.; FONT, V. (2015). Una propuesta para el análisis de las prácticas matemáticas de futuros profesores sobre derivadas. Bolema, Rio Claro, v. 29, n. 51, p.60-89, abr. 2015.

SIERPINSKA, A. Obstacles epistemologiques relatifs a la notion de limite. Recherches en Didactique des Mathèmatiques, Grenoble, v.6, n. 1, p.5-67, apr. 1985.

SOLER DE DIOS, B. Fractales para la construcción del concepto de límite en $4^{\circ}$ de ESO 2014. Thesis (Máster en Profesor de Educación Secundaria) - Departamento de Didáctica de las Matemáticas, Universidad Valencia, Valencia, 2014.

TALL, D. O.; SCHWARZENBERGER, R. L. Conflict in the Learning of Real Numbers and Limits. Mathematics Teaching, Derby, v. 82, p.44-49, mar. 1978.

VALDIVÉ, C.; GARBIN, S. Estudio de los esquemas conceptuales epistemológicos asociados a la evolución histórica de la noción de infinitesimal. Revista Latinoamericana de Investigación en Matemática Educativa, Ciudad de México, v. 11, n.3, p. 413-450, nov. 2008.

WILHELMI, M. R.; GODINO, J. D.; LACASTA, E. Epistemic configurations associated to the notion of equility in real numbers Recherches en Didactique des Mathèmatiques, Grenoble, v. 27, n. 1, p.53-82, apr. 2007.

WOODS, P. La escuela por dentro: La etnografía en la investigación educativa. Barcelona: Paidós, 1987.

ZELLINI, P. Breve historia del infinito. Madrid, España: Ediciones Siruela, 2004.

Submetido em 28 de Abril de 2020. Aprovado em 13 de Novembro de 2020. 